\title{
Dosimetric Comparison Of One Arc, Double Arc VMAT And IMRT Techniques in High Risk Prostate Cancer with Pelvic Nodal Radiation Therapy and High Doses
}

\author{
Berrin Inanc $^{1^{*}}$, Kubilay Inanc ${ }^{2}$, Bilgehan Coskun ${ }^{2}$, Ahmet Uyanoglu², Orhan Kızılkaya ${ }^{2}$ and Birsen Yücel $^{3}$ \\ ${ }^{1}$ Department of Radiation Oncology, S.B.U. Istanbul Education Research Hospital, Istanbul, Turkey \\ ${ }^{2}$ Department of Radiation Oncology, S.B.U Sisli Hamidiye Etfal Education and Research Hospital, Istanbul, Turkey \\ ${ }^{3}$ Department of Radiation Oncology, Cumhuriyet University School of Medicine, Sivas, Turkey
}

*Corresponding author: Berrin Inanc, Department of Radiation Oncology, S.B.U. Istanbul Education Research Hospital, Istanbul, TR-34098, Turkey, E-mail: byalcin77@hotmail.com

Received date: July 22, 2018; Accepted date: August 16, 2018; Published date: August 27, 2018

Copyright: $\odot 2018$ Inanc B, et al. This is an open-access article distributed under the terms of the Creative Commons Attribution License, which permits unrestricted use, distribution, and reproduction in any medium, provided the original author and source are credited.

\begin{abstract}
Purpose: Volumetric-modulated Arc Therapy (VMAT) is different from Intensity-modulated radiotherapy (IMRT) by the movement of gantry and rotation during treatment. Because of these features, there is a decrease in monitor unit (MU), better protection of organ at risk (OAR) and adequate PTV coverage. VMAT has become a standard therapy in prostate cancer. The aim of this study is to compare dosimetrically IMRT plan, single and double arc VMAT plans in high risk prostate cancer treated with high radiation $(<80 \mathrm{~Gy})$ doses.
\end{abstract}

Methods: Eleven high risk prostate cancer patients were treated with double-arc VMAT technique. The same patients were re-planned with single arc VMAT and IMRT technique. Radiotherapy was performed daily 2 Gy/ fraction to $46 \mathrm{~Gy}$ for pelvic area, $56 \mathrm{~Gy}$ for prostate+seminal vesicle, $80 \mathrm{~Gy}$ for prostate. The mean $\left(\mathrm{D}_{\text {mean }}\right)$, maximum $\left(D_{\max }\right)$, and minimum $\left(D_{\min }\right)$ dose of the planing target volume (PTV), conformity index $(C l)$, homogeneity index $(\mathrm{HI})$ and $\mathrm{MU}$ values and doses received by OARs were compared.

Results: The mean dose $(p=0.017)$, maximum dose $(p<0.001)$ of the PTV, $H I(p<0.001)$, MU values $(p<0.001)$, the $D_{25}$ of bladder $(p=0.011)$, the $D_{35}$ of bladder $(p=0.011)$, the $D_{25}(p=0.045)$ and $D_{35}(p=0.032)$ of rectum, the doses of right femur $\left(D_{5}, D_{25}, D_{50} ; p<0.001\right)$, the doses of left femur $\left(D_{25}, D_{50} ; p<0.001\right)$, and the mean dose of penile bulb i $(p=0.008)$ were statistically significant VMAT The single and double-arc VMAT and IMRT plans were compared in PTV maximum and HI. Both of them were lower in IMRT technique. In all techiques $\mathrm{Cl}$ had no differences. MU was significantly lower in arc techniques. The dose of $25 \%$ and $35 \%$ of bladder were higher in IMRT. There was no difference between doses of rectum. All doses of femur were superior in VMAT technique except $5 \%$ dose of left femur. The dose of penil bulb was higher in IMRT technique.

Conclusion: In especially high radiation doses, double-arc VMAT resulted in favorable dosimetry when compared single-arc VMAT and IMRT. Both VMAT techniques enabled a shorter MU and lower penile bulb bladder, rectum and femur doses, whereas IMRT provided a more homogeneous dose distribution.

VMAT techniques showed better protection in OARs except rectum, than IMRT. MU is significantly lower in VMAT techniques.

Keywords: VMAT; IMRT; High risk prostate cancer; Planning; High dose
Abbreviations:
VMAT: Volumetric Modulated Arc Therapy; IMRT: Intensity Modulated Radio Therapy; MU: Monitor Unit; PTV: Planning Target Volume; CI: Conformity Index; HI: Homogeneity Index; TV: Treatment Volume; OARs: Organs At Risk; RT: Radio Therapy; ADT: Androgen Deprivation Therapies; CT: Computerized Tomography; CTV: Clinical Target Volume; MV: Million Volts; MLC: Multi Leaf Collimators; PBS: Positive Biopsy Number

\section{Introduction}

Prostate cancer is the most common visceral cancer in men and is the second cause of cancer-related deaths [1]. Apparent frequency increases from age 50. In the treatment of prostate cancer, radiotherapy (RT) is a very important part of the curative approach.

It is known that the conventional doses used during radiotherapy treatment can not completely cure prostate cancer. In randomized phase three studies demostrated that dose escalation provided better disease-free survival in prostate cancer patients [2]. This effect was found especially in intermediate and high-risk patients [3]. However, escalated doses caused more side effects particularly late grade- 2 gastrointestinal toxicity [4,5]. With the introduction of new radiotherapy techniques such as IMRT and VMAT, side effects of RT 
was reduced as a result of less OARs volume in the treatment area $[6,7]$. From the view of this point IMRT and VMAT was considered much more in the curative treatment of prostate cancer [8-14].

The IMRT technique effectively adjusted the dose distribution and amount of normal tissue treated can be decreased thus limit this increased toxicity. IMRT is performed by multi-leaf collimators (MLC) in two ways: step and shoot (static) and dynamic (sliding). In this method, MLC move and form the segments while irradiation continues and gantry is fixed. VMAT, a more advanced technique of IMRT, is used 1-4 arcs during treatment [15-17]. In contrast to IMRT, this technique has gantry motion and can provide a constant or variable dose distribution by rotating around the prostate. In a randomized studie, the optimal homogeneous dose distribution and lowest OARs doses are provided by VMAT [18]. In many studies, VMAT has more reduced the duration of treatment and the amount of MU than IMRT $[19,20]$.

The aim of this study is to compare dosimetrically IMRT plans, single and double arc plans in high-risk prostate cancer treated with high radiation $(<80 \mathrm{~Gy})$ doses and profilactic pelvic nodal radiation theraphy.

\section{Materials and Methods}

Approval for this study was provided by the University of Health Science, Sisli Hamidiye Etfal Education and Research Hospital, Turkey, Human Research Ethics Committee (approval number: H-2017-1839)

Eleven high risk prostate cancer patients who were treated between 2012 and 2015 were included in this study in Sisli Hamidiye Etfal Training and Research Hospital Radiation Oncology Clinic. Patient age ranged from 57 to 69. Patients had prostate-specific antigen (PSA) scores ranging from 54 to 69 , with Gleason scores from 7 to 9. Patient characteristics were summarized in Table 1.

\begin{tabular}{|l|l|l|l|l|l|}
\hline Number & Gleason & PSA (ng/ml) & PBS & Stage & Age \\
\hline 1 & $4+4=8$ & 22.00 & $3 / 12$ & T2b & 70 \\
\hline 2 & $4+5=9$ & 15.35 & $12 / 12$ & T2b & 68 \\
\hline 3 & $4+4=8$ & 69.00 & $12 / 12$ & T4 & 68 \\
\hline 4 & $3+4=7$ & 21.35 & $10 / 10$ & T2b & 64 \\
\hline 5 & $4+4=8$ & 5.47 & $3 / 12$ & T1 & 59 \\
\hline 6 & $4+3=7$ & 13.00 & $12 / 12$ & T2b & 65 \\
\hline 7 & $3+4=7$ & 46.24 & $5 / 12$ & T2b & 68 \\
\hline 8 & $3+4=7$ & 28.80 & $8 / 12$ & T2b & 76 \\
\hline 9 & $4+4=8$ & 25.59 & $3 / 12$ & T2a & 75 \\
\hline 10 & $3+4=7$ & 26.50 & $7 / 12$ & T2b & 69 \\
\hline 11 & $4+4=8$ & 12.56 & $1 / 12$ & T2b & 57 \\
\hline
\end{tabular}

Table 1: Patient characteristics.

Neoadjuvant androgen-deprivation therapies (ADT) was delivered for 6 months Sisli Hamidiye Etfal Education and Research (Leuprolide Acetate $22.50 \mathrm{mg} / 3$ months and Bicalutamide $50 \mathrm{mg} /$ day) because all the patients were high risk prostate cancer.

\section{Simulation of patients}

All patients were in supine position and the legs and pelvis were fixed using a belly-board. Then computerized tomography (CT) was performed from the top of the iliac crests to the perineum with $3 \mathrm{~mm}$ CT slices. Before the CT scan, each patient's rectum was empty. The bladder was filled to a degree that was sustainable and reproducible for daily treatment. Magnesium hydroxide was given to all patients to reduce side effects of RT to bowel.

All of the patients were planned with 7 field sliding-window IMRT technique, single and double-arc VMAT techniques. Varian Eclips version 11.0 software (ECLIPS Varian Medical Systems, Inc., Palo Alto, CA, USA) was used for RT contouring and RT planning.

A physician contoured gross tumor volume (GTV) to included all known disease. In these patients who underwent elective pelvic nodal radiotherapy, obturator, internal, external iliac and presacral lymph nodes were included in the RT field.

\section{RT plans}

- Clinical target volume (CTV): Pelvic lymph nodes as CTV3, seminal vesicle(SV)+prostate as CTV2 and only prostate as CVT1.

- planning target volume (PTV): The margin of pelvic lymph nodes were $0.7 \mathrm{~mm}$. The margin of CTV2 and CTV1 were $8 \mathrm{~mm}$ in all direction, except posterior direction. The margin of posterior direction was $5 \mathrm{~mm}$. Therefore organ movements and set-up changes were taken into account. The prescription dose was to cover $95 \%$ of PTV, with the maximum dose in the PTV no more than $107 \%$ of prescribtion dose.

- OAR: Rectum, bladder, both femur head and penile bulb were considered organ at risk.

- RT dose: From 2 Gy daily to 46 Gy for pelvic area, 56 Gy for prostate+seminal vesicle and $80 \mathrm{~Gy}$ for prostate.

\section{Treament Planning}

All high-risk prostate patients were planned in three techniques: 7 field dynamic IMRT, single and double-arc. All of them had same dose-rate which was $600 \mathrm{MU} / \mathrm{min}$ and we used $6 \mathrm{MV}$ (million volts) photon energy in all techniques.

\section{IMRT planning}

Plans were created using the Varian Clinac IX model Linear Accelerator which has 120-leaf millenium MLC and were performed on the Varian Eclips treatment computer with an anisotropic analytical algorithm (AAA v.10.28). In the IMRT plans there was 51 equally spaced gantry angles $\left(0^{\circ}, 51^{\circ}, 102^{\circ}, 153^{\circ}, 204^{\circ}, 255^{\circ}, 306^{\circ}\right)$ and each field was created using collimator angle 0 . After the fields were determined, optimization process was started. In the optimization process, prescription dose was 80 Gy to cover $95 \%$ of PTV and OARs were tried to received minimum dose. MLC movements were smoothed by applying general fluence correction.

\section{VMAT planning}

VMAT Planning was calculated at $2.5 \mathrm{~mm}$ dose grid intervals using AAA in Varian Eclipse treatment planning system (Version 11.0 Varian Medical Systems, Palo Alto, CA).

Treatment plans had same rules. These rules: 
Citation: Inanc B, Inanc K, Coskun B, Uyanoglu A, Kizilkaya O, et al. (2018) Dosimetric Comparison Of One Arc, Double Arc VMAT And IMRT Techniques in High Risk Prostate Cancer with Pelvic Nodal Radiation Therapy and High Doses. J Nucl Med Radiat Ther 9: 370 . doi: $10.4172 / 2155-9619.1000370$

Page 3 of 6

- Isosentrine point was placed in the middle of PTV.

- Two full arcs were created using the Eclips Arc Geometry tool.

- The first arc was created with 181-179 degrees clockwise by rotation 30 degrees of collimator.

- The second arc clockwise was created with 179-181 degrees opposite clockwise by rotation 330 degrees of collimator.

In VMAT plans combination of dynamic MLC collimation and arc was used. The target volumes were defined as first priority. Then OARs (rectum, bladder, bilateral femur heads and penile bulb) were defined as second priorities. The normalization point was chosen such that $100 \%$ of the defined dose would be delivered to $95 \%$ the PTV.

\section{Assessment of the Plans}

In the evaluation of the plans, single arc, double arcs and 7 fields IMRT schedules were compared for each patient. PTV minimum $\left(D_{2}\right)$, PTV maximum $\left(\mathrm{D}_{98}\right)$ and mean were assessed. The tolerance doses of OAR were defined according to RTOG 0815 . The average dose of $D_{15}$, $\mathrm{D}_{25}, \mathrm{D}_{35}$ and $\mathrm{D}_{50}$ received by the bladder $\mathrm{D}_{15}, \mathrm{D}_{20}, \mathrm{D}_{25}, \mathrm{D}_{35}, \mathrm{D}_{50}$ by the rectum $D_{5}, D_{25}, D_{50}$ by the right and left femur had and mean dose of penile bulb At the same time MU of plans were evaluated. The meaning is $D_{2}, D_{98}, D_{5}, D_{15}$ shows the received radiation dose of $2 \%$, $98 \%, 5 \%, 15 \%$ of the volume.

\section{CI and HI were compared in all three planes according to the following definitions}

Homogeneity index (HI): The ideal of $\mathrm{HI}$ is close to zero and demonstrates the homogeneity distribution of dose in PTV. The formula is:

Homogeneity index $(\mathrm{HI})=\mathrm{D}_{2 \%}{ }_{-} \mathrm{D}_{98 \%} / \mathrm{D}_{50 \%}$

Conformity Index (CI): CI optimization is valid for dose homogeneity in PTV and the ideal value of $\mathrm{CI}$ is 1 . The formula is:

\section{Conformity Index $(\mathrm{CI})=\mathrm{TV} / \mathrm{PTV}$}

SPSS 15.0 for Windows program was used for statistical analysis. Descriptive statistics were given median values for numerical variables. In the nonparametric test, subgroup analyzes were performed by Wilcoxon test and interpreted by Bonferroni correction. The ratios of categorical variables among the groups were tested by chi square analysis. Bonferroni correction is interpreted when the conditions were not ensured. Statistical significance level of alpha was accepted as $\mathrm{p}<0.05$.

\section{Results}

Patient age ranged from 57 to 69. Patients had prostate-specific antigen (PSA) scores ranging from 54 to 69, with Gleason scores from 7 to 9 . Patient characteristics were summarized in Table 1.

Table 2 shows the results of dose distribution with single-arc and double-arc technique and IMRT. $\mathrm{D}_{\text {mean }}(\mathrm{p}=0.017), \mathrm{D}_{\max }(\mathrm{p}<0.001), \mathrm{HI}$ $(p<0.001)$, and MU $(p<0.001)$ were statistically significant in the dose distribution of PTV. The $\mathrm{D}_{25}(\mathrm{p}=0.011)$ and $\mathrm{D}_{35}(\mathrm{p}=0.011)$ of bladder were statistically different the groups.The $\mathrm{D}_{25}(\mathrm{p}=0.045)$ and $\mathrm{D}_{35}$ $(\mathrm{p}=0.032)$ doses of rectum were statistically different between the groups. When the doses of right and left femurs were examined, the difference between the groups was determined for all other doses except the left femur $D_{5}(p<0.001$ for all). The mean dose of penile bulb was also different the groups $(\mathrm{p}=0.008)$.

\begin{tabular}{|c|c|c|c|c|}
\hline & Single arc & Double arc & 7 field IMRT & $p$ values \\
\hline \multicolumn{5}{|l|}{ PTV } \\
\hline $\mathrm{D}_{\text {Mean }}$ & $77.18 \mathrm{~Gy}$ & $77.94 \mathrm{~Gy}$ & $77.40 \mathrm{~Gy}$ & 0.017 \\
\hline$D_{\max }$ & $84.30 \mathrm{~Gy}$ & $83.60 \mathrm{~Gy}$ & $82.31 \mathrm{~Gy}$ & $<0.001$ \\
\hline $\mathrm{D}_{\mathrm{Min}}$ & $65.41 \mathrm{~Gy}$ & $65.03 \mathrm{~Gy}$ & $64.93 \mathrm{~Gy}$ & 0.434 \\
\hline $\mathrm{Cl}$ & 1.09 & 1.08 & 1.07 & 0.726 \\
\hline $\mathrm{HI}$ & 0.8 & 0.6 & 0.5 & $<0.001$ \\
\hline MU & 1139 & 1290 & 3021 & $<0.001$ \\
\hline
\end{tabular}

Bladder

\begin{tabular}{|l|l|l|l|l|}
\hline$D_{15}$ & 66.96 & 66.12 & 68.85 & 0.319 \\
\hline$D_{25}$ & 54.9 & 53.99 & 58.85 & 0.011 \\
\hline$D_{35}$ & 48.24 & 47.51 & 52.79 & 0.011 \\
\hline$D_{50}$ & 42.35 & 39.85 & 44.2 & 0.319 \\
\hline
\end{tabular}

Rectum

\begin{tabular}{|l|l|l|l|l|}
\hline$D_{15}$ & 66.48 & 64.74 & 65.5 & 0.251 \\
\hline$D_{20}$ & 61.2 & 57.4 & 58.67 & 0.175 \\
\hline$D_{25}$ & 55.98 & 50.66 & 52.91 & 0.045 \\
\hline$D_{35}$ & 48.49 & 46.69 & 46.19 & 0.032 \\
\hline$D_{50}$ & 43.43 & 38.99 & 38.56 & 0.474 \\
\hline
\end{tabular}

Right femur

\begin{tabular}{|l|l|l|l|l|}
\hline$D_{5}$ & 42.55 & 42.97 & 45.05 & $<0.001$ \\
\hline$D_{25}$ & 29.16 & 30.47 & 34.68 & $<0.001$ \\
\hline$D_{50}$ & 23.88 & 25.82 & 31.16 & $<0.001$ \\
\hline
\end{tabular}

\section{Left femur}

\begin{tabular}{|c|c|c|c|c|}
\hline$D_{5}$ & 43.22 & 43.03 & 45.06 & 0.099 \\
\hline $\mathrm{D}_{25}$ & 31.08 & 31.32 & 35.09 & $<0.001$ \\
\hline$D_{50}$ & 25.79 & 23.79 & 31.64 & $<0.001$ \\
\hline \multicolumn{5}{|c|}{ Penile bulb } \\
\hline Mean & 37.1 & 38.67 & 40.83 & 0.008 \\
\hline
\end{tabular}

Table 2: Comparison of the doses received by PTV and OARs in dose distribution compared to 7 field IMRT, single and double VMAT techniques.

Table 3 show that statistically difference among to single-arc vs. double-arc, single-arc vs. 7 field IMRT and double-arc vs. 7 field IMRT. A statistically significant difference in PTV mean was found between the techniques $(p=0.017)$. There was no statistically significant difference between the groups in the subgroup analyzes (Table 3). 
Citation: Inanc B, Inanc K, Coskun B, Uyanoglu A, Kizilkaya O, et al. (2018) Dosimetric Comparison Of One Arc, Double Arc VMAT And IMRT Techniques in High Risk Prostate Cancer with Pelvic Nodal Radiation Therapy and High Doses. J Nucl Med Radiat Ther 9: 370. doi: $10.4172 / 2155-9619.1000370$

Page 4 of 6

\begin{tabular}{|c|c|c|c|c|}
\hline & $P$ values & Single vs. double Arc & Single vs. 7 field IMRT & Double vs. 7 field IMRT \\
\hline \multicolumn{5}{|l|}{ PTV } \\
\hline$D_{\text {mean }}$ & $P$ & 0.096 & 0.245 & 0.074 \\
\hline $\mathrm{D}_{\max }$ & $\mathrm{p}$ & 0.019 & 0.001 & 0.011 \\
\hline $\mathrm{HI}$ & $\mathrm{p}$ & 0.003 & 0.001 & 0.001 \\
\hline MU & $\mathrm{p}^{*}$ & 0.065 & $<0.001$ & $<0.001$ \\
\hline \multicolumn{5}{|c|}{ Bladder } \\
\hline $\mathrm{D}_{25}$ & $\mathrm{p}$ & 0.041 & 0.397 & 0.011 \\
\hline $\mathrm{D}_{35}$ & $\mathrm{p}$ & 0.052 & 0.300 & 0.006 \\
\hline \multicolumn{5}{|c|}{ Rectum } \\
\hline $\mathrm{D}_{25}$ & $P$ & 0.016 & 0.363 & 0.778 \\
\hline $\mathrm{D}_{35}$ & $P$ & 0.016 & 0.826 & 0.925 \\
\hline \multicolumn{5}{|c|}{ Right Femur } \\
\hline $\mathrm{D}_{5}$ & $p^{*}$ & 0.299 & 0.003 & 0.001 \\
\hline $\mathrm{D}_{25}$ & $p^{*}$ & 0.850 & 0.001 & $<0.001$ \\
\hline $\mathrm{D}_{50}$ & $p^{*}$ & 0.911 & $<0.001$ & $<0.001$ \\
\hline \multicolumn{5}{|c|}{ Left Femur } \\
\hline $\mathrm{D}_{25}$ & $p^{*}$ & 0.850 & 0.001 & $<0.001$ \\
\hline$D_{50}$ & $\mathrm{P}^{*}$ & 0.574 & $<0.001$ & $<0.001$ \\
\hline \multicolumn{5}{|c|}{ Penile bulb } \\
\hline Mean & $p^{*}$ & 0.012 & 0.006 & 0.027 \\
\hline
\end{tabular}

Table 3: Comparison of $P$ values parameter for single, double Arc and 7 field IMRT.

There was a statistically significant difference between the singlearc, double-arc and 7 field IMRT in PTVmax averages (84.30 Gy, 83.60 Gy, $82.31 \mathrm{~Gy}$, respectively; $\mathrm{p}<0.001)$. In the subgroup analyzes, singlearc vs. IMRT and double-arc vs. IMRT, the mean PTV max was statistically sinificant $(\mathrm{p}=0.001, \mathrm{p}=0.011$; respectively).

The homogeneity index was better 7 field IMRT than single-arc and double-arc technigue $(\mathrm{p}<0.001)$. The difference between the single-arc vs. double-arc, single-arc vs. 7 field IMRT and double-arc vs. 7 field IMRT was statistically significant $(\mathrm{p}=0.003, \mathrm{p}=0.001, \mathrm{p}=0.001$; respectively). The MU average was significantly better in single-arc and double-arc technique than the 7-field IMRT technique (1139, 1290, 3021, respectively; $\mathrm{p}<0.001$ ).

In terms of OAR, the bladder statistically differences were found for $\mathrm{D}_{25}$ and $\mathrm{D}_{35}$ measurements. In 7 field IMRT technique, $\mathrm{D}_{25}$ and $\mathrm{D}_{35}$ doses higher than single-arc and double-arc technique (58.85 Gy, 52.79 $\mathrm{Gy}$, respectively; $\mathrm{p}=0.011$ ). In both doses, the differences in the levels of the double-arc vs. 7-field IMRT techniques were statistically significant $(\mathrm{p}=0.011, \mathrm{p}=0.006)$.

Rectum $\mathrm{D}_{25}$ and $\mathrm{D}_{35}$ doses by double-arc and 7 field IMRT were basically equivalent. But in a single arc these doses (55.98 Gy, 48.49
Gy) were found to be higher and this is statistically significant ( $\mathrm{p}=0,045, \mathrm{p}=0,032$; respectively). The differences in single-arc $v S$. double-arc comparision were statistically significant ( $\mathrm{p}=0.016$ for both doses).

Statistically significant differences were found in all measurements except for left femur $\mathrm{D}_{5}$ ( $\mathrm{p}<0.001$ for all) in the femur evaluations. In all measurements, 7-field IMRT were statistically different from singlearc and double-arc techniques ( $\mathrm{p}<0.001)$ (Tables 2 and 3 ).

Penile bulb mean doses were lower in the single-arc technique and this was statistically significant $(37.10 \mathrm{~Gy}, \mathrm{p}=0.008)$. The difference between the single-arc vs. double-arc, single-arc vs. 7 field IMRT and double-arc vs. 7 field IMRT was statistically significant $(\mathrm{p}=0.012$, $\mathrm{p}=0.006, \mathrm{p}=0.027$; respectively).

\section{Discussion}

Today, in parallel with the developments in technology, radiotherapy applications are alsovery encouraging developments. New radiotherapy devices and planning techniques have given higher doses to the tumor site, while limiting dose to surrounding tissues and organs. These have played an important role in the treatment of high 
Page 5 of 6

risk prostate cancer. Dose escalation in prostate treatments has been demostrated to improve local control $[2,3,20]$

There is few study with dosimetric comparison of high dose $(>80$ Gy) radiotherapy with pelvic nodal irradiation in patients with highrisk prostate cancer. Other prostate planing studies, pelvic nodal radiotherapy is not applied and radiotherapy is given $76-78 \mathrm{~Gy}[20,21]$. The same time, the dose to the OAR was compared by determining the percentage volume $(\mathrm{V})$ of an organ receiving dose. But in our study the opposide was used.When viewed from this perspective it is only study done.

In our study, the pelvic lymph node volumes were defined according to the RTOG consensus [22]. We evaluated doses of PTV maximum, minimum, mean dose, $\mathrm{HI}, \mathrm{CI}$, and doses that were deliverd to bladder, rectum, right and left femurs hads and penile bulb doses. Small but statistically significant differences were noted among the 3 techniques.

In contrast to other studies [19-23], in our studies PTV max and HI were detected lower in 7 field IMRT technique than arc techniques. The IMRT technique provided a more homogeneous dose distribution. This situtions could be because of irradiated pelvic lymph nodes and radiations doses.There was only prostate irradiation in other studies and radiation doses was given at 76-78 Gy.

Organ-at-risk dose sparing was very similar for the 3 techniques. We found that arc techniques spared the rectum, bladder, femurs and penile bulb. In our study, in double arc technique bladder was received lower dose than IMRT at D25 and D35. Radiation exposure to rectum was highest using single-arc techique at $\mathrm{D}_{25}$ and $\mathrm{D}_{35}$. It was found to be compitable literature [24].

There were statistically significant differences in 7 field IMRT and double arc of $25 \%$ and $35 \%$ doses. We found $25 \%$ dose of bladder 53.99 Gy double arc, 58.85 Gy in IMRT and 35\% dose of bladder 47.51 Gy in double arc, 52.79 Gy in IMRT.

There was no statistically significant difference between arc techniques and 7 field IMRT technique in the doses received by the rectum, whereas $25 \%$ and $35 \%$ doses of double arc and single arc techniques were found to be statistically significant (25\% doses were 50.66 Gy, 55.98 Gy and 35\% doses were 48.49 Gy and 46.69 Gy, respectively ).

The arc technique was superior to the IMRT in all doses except the D5 5\% dose in left femur doses. Arc technique become less conformal in the low-dose range $[20,25,26]$. This can be attributed to the dose being delivered from all directions. In IMRT plans, radiation dose is only depoited along the path of fixed gantry angles. As a result of femur receiving a low dose in arc techique is increased compared to IMRT.

The dose of penile bulb in the double-arc technique was less than both the single-arc and IMRT. The MU was significantly reduced by the use of arc techniques. The lower MU combining with less beam mode-up procedures resulted in a much shorter treatment time with arc treatment. Adamson et al. [27] found that the shorter treatment time could reduce the CTV margins, so that the normal tissues would be exposed to less doses.

Especially in high-doses, arc techniques were demostrated to deliver lower dose to the bladder, rectum, penile bulb and heads of femur and when compared to 7 field IMRT.

\section{Conclussion}

Pelvic nodal irradiation in combination with high-dose radiotherapy applications as a result, double-arc technique has been shown better bladder, femur and penile bulb protection compared to 7 field IMRT techniques. In additional MU value was significantly lower in arc techniques. In high dose radiotherapy applications, arc techniques have been found better than 7-field IMRT but in terms of HI, 7-field IMRT technique more effective.

\section{Declarations}

Ethics approval and consent to participates: 26/12/2017 1839

\section{Consent for Publication}

\section{6/12/2017 1839}

Availability of data and materials: Data sharing is available for this article.

\section{Funding}

Not applicable.

\section{Competing Contributions}

The authors declare that they have no competing interests. The authors have no financial disclosures to declare, no conflicts of interest to report and have no commercial or proprietary interest.

\section{Acknowledgements}

Not applicable.

\section{References}

1. Cooperberg MR, Cowan J, Broering JM, Carroll PR (2008) High-risk prostate cancer in the United States 1990-2007. World J Urol 26: 211-218.

2. Viani GA, Stefano EJ, Afonso SL (2009) Higher than convantional radiation doses in localized prostate cancer treatment: A meta-analysis of randomized controlled trials. Int J Radiat Oncol Biol Phys 74: 1405-1418.

3. Kuban DA, Tucker SL, Dong L, Starkschall G, Huang EH, et al. (2008) Long-term results of the M.D. Anderson randomized dose escalation trial for prostate cancer. Int J Radiat Oncol Biol Phys 70: 67-74.

4. Zelefsky MJ, Levin EJ, Hunt M, Yamada Y, Shippy AM, et al. (2008) Incidence of late rectal and urinary toxicities after three-dimensional conformal radiotherapy and intensity-modulated radiotherapy for localized prostate cancer. Int J Radiat Oncol Biol Phys 70: 1124-1129.

5. Peeters ST, Heemsbergen WD, van Putten WL, Slot A, Tabak H, et al. Acute and late complications after radiotherapy for prostate cancer: Results of a multicenter randomized trial comparing 68 Gy to $78 \mathrm{~Gy}$. Int J Radiat Oncol Biol Phys 61: 1019-1034.

6. Amin N, Konski AA (2012) Intensity-modulated radiation therapyfor prostat cancer is cost effective and improves therapeutic ratio. Expert Rev Pharmacoecon Outcomes Res 12: 447-450.

7. Dinan MA, Robinson TJ, Zagar TM, Scales CD (2012) Canges in initial treatment for prostate cancer among Medicare beneficiarie. Int J Oncol Biol Phys 82: e781-e786.

8. Kupelian PA, Reddy CA, Carlson TP, Altsman KA, Willoughby TR (2002) Preliminary observations on biochemical relapse-free survival rates after short-course intensity-modulated radiotherapy (70 Gy at $2.5 \mathrm{~Gy} /$ fraction) for localized prostate cancer. Int J Radiat Oncol Biol Phys 53: 904-912.

9. Kupelian PA, Reddy CA, Carlson TP, Willoughby TR (2002) Dose/volume relationship of late rectal bleeding after external beam radiotherapy for 
Citation: Inanc B, Inanc K, Coskun B, Uyanoglu A, Kizilkaya O, et al. (2018) Dosimetric Comparison Of One Arc, Double Arc VMAT And IMRT Techniques in High Risk Prostate Cancer with Pelvic Nodal Radiation Therapy and High Doses. J Nucl Med Radiat Ther 9: 370. doi: $10.4172 / 2155-9619.1000370$

Page 6 of 6

localized prostate cancer: Absolute or relative rectal volume? Cancer J 8: 62-66.

10. Shunichi N, Shigeto I, Tatsuo T, Sadafumi K, Masaaki K, et al. (2006) Health-related quality of life after intensity modulated radiation therapy for localized prostate cancer: Comparison with conventional and conformal radiotherapy. Jpn J Clin Oncol 36: 224-230.

11. Sanguineti G, Cavey ML, Endres EJ, Franzone P, Barra S, et al. (2006) Does treatment of the pelvic nodes with IMRT increase late rectal toxicity over conformal prostate only radiotherapy to $76 \mathrm{~Gy}$ ? Strahlenther Onkol 182: 543-549.

12. Veldeman L, Madani I, Hulstaert F, De Meerleer G, Mareel M, et al. (2008) Evidence behind use of intensity-modulated radiotherapy: A systematic review of comparative clinical studies. Lancet Oncol 9: 367-375.

13. Zelefsky MJ, Fuks Z, Happersett L, Lee HJ, Ling CC, et al.(2000) Clinical experience with intensity modulated radiation therapy (IMRT) in prostate cancer. Radiother 55: 241-249.

14. Zelefsky MJ, Fuks Z, Hunt M, Lee HJ, Lombardi D, et al. (2001) High dose radiation delivered by intensity modulated conformal radiotherapy improves the outcome of localized prostate cancer. J Urol 166: 876-881.

15. Bzdusek K, Friberger H, Eriksson K, Hardemark B, Robinson D, et al. (2009) Development and evaluation of an efficient approach to volumetric arc therapy planning. Med Phy 36: 2328-2339.

16. Otto $\mathrm{K}$ (2008) Volumetric modulated arc therapy: IMRT in a single gantry arc. Med Phy 35: 310-317.

17. Yu CX (1995) Intensity-modulated arc therapy with dynamic multileaf collimation- An alternative to tomotherapy. Phys Med Biol 40: 1435-1449.

18. Palma D, Vollans E, James K, Nakano S, Moiseenko V, et al. (2008) Volumetric modulated arc therapy for delivery of prostate raditheraphy: Comparison with intensity-modulated radiotherapy and threedimensional conformal radiotherapy. Int J Oncol Biol Phys 72: 996-1001.

19. Davidson MT, Blake SJ, Batchelar DL, Cheung P, Mah K (2011) Assessing the role of volumetric modulated arc therapy (VMAT)relative to IMRT and helical tomotherapy in the management of localized, locally advanced and post-operative prostat cancer. Int J Oncol Biol Phys 80: 1550-1558.

20. Wolff D, Stieler F, Welzel G, Lorenz F, Abo-Madyan Y, et al. (2009) Volumetric modulated arc therapy (VMAT) vs. serial tomotheraphy, stepand-shoot IMRT and 3D-conformal RT for prostat cancer. Radiother Oncol 93: 226-233.

21. Tsai CL, Wu JK, Chao HL, Tsai YC, Cheng JC (2011) Treatment and dosimetric advantages between VMAT, IMRT, and helical tomotherapy in prostate cancer. Med Dosim 36: 264-271.

22. Lawton CA, Michalski J, El-Naqua I, Buyyounouski MK, Lee WR, et al. (2009) RTOG GU radiation oncology specialists reach consensus on pelvic lymph node volumes for high-risk prostate cancer. Int J Radiat Oncol Biol Phys 74: 383-38.

23. Fontenot JD, King ML, Johnson SA, Wood CG, Prive MJ, et al. (2012) Single-arc volumetric modulated arc therapy can provide dose distributions equivalent to fixed-beam intesity modulated radiation therapy for prostatic irradiation with seminal vesicle and/or lymph node involvement. Br J Radiol 85: 231-236.

24. Sze HC, Lee MC, Hung WM, Yau TK, Lee AW (2012) Rapid Arc radiotherapy planning for prostate cancer: Single-arc and double-arc techniques vs. intensity modulated radiotherapy. Med Dosim 37: 87-91.

25. Yoo S, Wu QJ, Lee WR, Yin FF (2010) Radiotheraphy treatment plans with RapidArc for prostate cancer involving seminal vesicles and lymph nodes. Int J Oncol Biol Phys 76: 935-942.

26. Kajer KF, Ohlhues L, Medin J, Korreman S (2009) RapidArc volumetric modulated therapy planning for prostate cancer patients. Acta Oncol 48: 227-232.

27. Adamson J, Wu Q (2010) Prostate intrafraction motion assessed by simultaneous kilovoltage fluoroscopy at megavoltage delivery I: Clinical observations and pattern analysis. Int J Radiat Oncol Bio Phys 78: 1563-1570. 